Annual Review of Microbiology

Vol. 15. Edited by Charles E. Clifton, in association with Sidney Raffel and Mortimer P. Starr. Pp. viii + 349. (Palo Alto, Calif.: Annual Reviews, Inc., 1961.) 7 dollars.

THE fifteenth Annual Review of Microbiology provides concise surveys of literature covering a wide range of topics; in this respect it lives up to the standard set by its predecessors. The volume contains thirteen reviews, cites more than two thousand references and includes a cumulative index of authors and chapters for Volumes 11-15.

Microbiological literature has, during the past decade, become liberally sprinkled with jargon. Most microbiologists are now familiar with the terms 'chemostat' and 'bactogen', but 'auxanometer' and 'symbiocon' may leave many puzzled. The principles of these and other devices now used for the continuous culture of micro-organisms are admirably presented by James.

Studies of microbial metabolism continue to reveal new synthetic capabilities in micro-organisms: the biosynthesis of $\mathrm{C}_{2}, \mathrm{C}_{3}$ and $\mathrm{C}_{4}$ compounds from $\mathrm{C}_{1}$ units is discussed in a comprehensive review by Quale. All who study microbial metabolism will, ultimately, be faced with problems of cell permeability and membrane transport. Cirillo points out that, until recently, it has been common practice either to ignore these problems or eliminate them by the mechanical disruption of cells. This is no longer the case. Much has been learnt in recent years about active transport mechanisms and 'permeases'; these studies have been well summarized by Cirillo in an article entitled "Sugar Transport in Micro-organisms".

Two articles in the present volume will be of the greatest interest to virologists. Questions of virus structure are discussed by Colter and Ellem; Zhdanov reviews recent experience with anti-viral vaccines. This latter contribution contains some interesting information about the relative merits of different poliomyelitis vaccines.

Other topics reviewed include: physiology of actinomycetes ; fine structure of protozoa; interactions between pesticides and soil micro-organisms; the family Brucellaceae in veterinary research; phagehost relationships in some genera of medical significance; plant-nematode inter-relationships; gaseous sterilization and antigenic variation in unicellular micro-organisms.

B. A. Newton

The Ovary

Vol. 1. Pp. xiii +619 . 157s. 6d. Vol. 2. Pp. xiii +600 . 157s. Edited by Sir Solly Zuckerman. Assisted by Anita M. Mandl and Peter Eckstein. (New York: Academic Press, Inc.; London: Academic Press, Inc. (London), Ltd., 1962.)

7 HIS magnificent treatise will certainly long remain a standard reference work for the literature on the morphology and function of the ovary.

Volume 1 consists of eleven chapters and covers the development and structure of the ovary, including its histochemistry, the ovarian cycle, ovarian pituitary relationship, the mechanism of ovulation, ovarian physiology in the non-pregnant and pregnant female, the menopause, and derangements in ovarian function.

The twenty-three chapters of Volume 2 deal with such varied problems as the chemistry and biochemistry of ovarian hormones, the experimental embryology of the ovary, the actions of ovarian hormones on the body, the influence of nutrition and external factors on the ovary, relationship between ovarian hormone secretion and behaviour, transplantation of the ovary, and the relationship between tumorogenesis and the ovary.

Each chapter is written by specialists, well recognized in their respective fields, and, thanks to the excellent editorial work of Sir Solly Zuckerman, the whole treatise has a character of harmonious unity despite the multiplicity of necessarily overlapping subjects

It would be impossible to review each chapter of an extensive treatise of this kind in detail, but there can be no doubt about the value of these two volumes not only to endocrinologists but also to comparative anatomists, zoologists and experimental embryologists. The treatise is illustrated by numerous photographs, graphs, and tables; its usefulness is greatly enhanced by carefully prepared author-and subject-indexes.

HaNs Selye

\section{Science and World Affairs}

History of the Pugwash Conferences. By Prof. J. Rotblat. Pp. $92+4$ plates. (London: Dawsons of Pall Mall, 1962.) 8s. 6d. paper bound, 14s. cloth bound.

THE most recent Pugwash Conferences have met in the United Kingdom: the first at Cambridge on August 25 was attended by 60 specialists on disarmament and arms control; the second in London on September 3, when some 200 scientists from many nations sought solutions to some of the problems created or made tractable by the modern growth of science. Prof. Rotblat's readable account of the origin and development of these Conferences on science and world affairs as an important and effective channel of communication between scientists for the study and discussion of the most complex problems now facing mankind thus appears at a most opportune moment.

It gives a concise, purely factual account of the first eight conferences, and although Prof. Rotblat does not attempt to discuss in general terms the organization of international discussion among scientists, its effectiveness, or the relation of such discussion to Government action, he provides all the material required for an independent and impartial assessment of what has already been achieved by these conferences. He appends to his account the original Russell-Einstein manifesto of December 1954 from which the movement may be said to have stemmed and the several statements issued by the successive Conferences, including the Vienna Declaration of 1958, and the detailed proposals for international co-operation in science which form the substance of the statement from the seventh Conference last September, and there are lists of the participants in all these Conferences. He is content to let the facts speak for themselves, and the success which the movement has already achieved is manifestly such as makes the book one which has strong claims on the attention of scientists generally.

Prof. Rotblat has earned the gratitude of all scientists who believe that science has in its power to make a serious and constructive contribution to world peace and order. His book should make a definite contribution to the understanding of what the two Conferences in the United Kingdom represent and their implications for human welfare and scientific advancement. $R$. BRIGHTMAN 